\section{rev Psi}

Revista de Psicología (UNLP)

https://revistas.unlp.edu.ar/revpsi

Artículo de investigación

\title{
Desarmar(se) varón - construir(se)padre: intervenciones psicoanalíticas con jóvenes varones en contexto de encierro punitivo
}

\author{
Irma Colanzi ${ }^{1}$ \\ Correspondencia \\ irma_ciro@hotmail.com \\ Filiaciones institucionales \\ ${ }^{1}$ Consejo Nacional de Investigaciones \\ Científicas y Técnicas (CONICET, Argentina)
}

\section{Resumen}

A partir de los desarrollos de los estudios de género, las masculinidades y la teoría cuir problematizaremos, en primer lugar, cómo el psicoanálisis explica al sujeto en vínculo con las concepciones culturales de masculinidad y feminidad. En segundo lugar, analizaremos cuáles son las intervenciones clínicas posibles en la cárcel. Al momento de reflexionar sobre nuestras herramientas como psicoanalistas, se analizarán las lógicas de producción de un dispositivo terapéutico en una unidad penitenciaria atendiendo a dos especificidades: las lógicas del encierro punitivo y los lazos sexo-afectivos de los jóvenes varones privados de libertad. Partiremos de la noción de intervención, que atendiendo a estas particularidades, y entendiendo la ética psicoanalítica orientada a la subversión del sujetx, se ve mutilada al no incluir las categorías de análisis y praxis de los estudios de género.

\section{Palabras clave}

masculinidades | género | lazos sexo-afectivos | intervenciones psicoanalíticas en cárceles

\section{Cómo citar}

Colanzi, I. (2020). Una lectura sobre

la diferencia sexual y la época. Revista de Psicología, 19(2), 174-192. doi:

$10.24215 / 2422572$ XE069

\section{Recibido}

11 may. 2020

Aceptado

Publicado

5 nov. 2020

Editor

DOI

$10.24215 / 2422572 \times E 069$
Claudia E. De Casas (Facultad de Psicología,

UNLP, Argentina) y Nicolás Alessandroni

(Facultad de Psicología, UAM, España).
ISSN

2422-572X

Licencia

(c) Copyright: Colanzi, I. Licencia de Cultura Libre CC-BY 4.0

Entidad editora

RevPsi es una publicación de la

Facultad de Psicología (Universidad

Nacional de La Plata, Argentina)

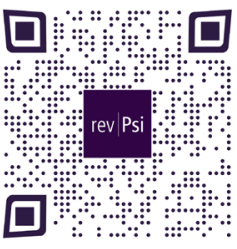

ACCESO ABIERTO DIAMANTE 


\title{
Desarmar (ser) homem - construir (ser) pai: intervenções psicanalíticas com jovens no contexto de confinamento punitivo
}

\section{Resumo}

Partindo dos desenvolvimentos nos estudos de gênero, masculinidades e teoria cuir, discutiremos primeiramente como a psicanálise, enquanto construção teórica da modernidade, explica o assunto em conexão com as concepções culturais de masculinidade e feminilidade. Em segundo lugar, analisaremos quais são as possíveis intervenções clínicas na prisão. Ao refletir sobre nossas ferramentas como psicanalistas, será analisada a lógica de produção de um dispositivo terapêutico em uma unidade penitenciária, atendendo a duas especificidades: a lógica do confinamento punitivo e os laços afetivo-sexuais de jovens carentes. da liberdade. Para tanto, partiremos da noção de intervenção que, atendendo a essas particularidades, e compreendendo a ética psicanalítica orientada para a subversão do sujeito, é mutilada por não incluir as categorias de análise e práxis dos estudos de gênero.

\section{Palavras-chave}

masculinidades | gênero | vínculos afetivo-sexuais | intervenções psicanalíticas nas prisões

\section{Disarm(ing) as a male - build(ing) as a father: psychoanalytic inter- ventions with young men in the context of punitive confinement}

\author{
Abstract \\ Starting from the developments in gender studies, masculinities and queer theory, \\ we will first discuss how psychoanalysis, as a theoretical construction of modernity, \\ explains the subject in connection with cultural conceptions of masculinity and \\ femininity. Second, we will analyze what are the possible clinical interventions in \\ prison. When reflecting on our tools as psychoanalysts, the logics of production of a \\ therapeutic device in a penitentiary unit will be analyzed, attending to two specificities: \\ the logics of punitive confinement and the sex-affective ties of young men deprived of \\ freedom. To do this, we will start from the notion of intervention, which, taking into \\ account these particularities, and understanding the psychoanalytic ethics oriented \\ towards the subversion of the subject, is mutilated by not including the categories of \\ analysis and praxis of gender studies.
}

\section{Keywords}

masculinities | gender | sex-affective bonds | psychoanalytic interventions in prisons 
Las intervenciones psicoanalíticas se sustentan en una premisa ético - política que configura una práctica propiciatoria de la emergencia y subversión de lxs sujtxs. En tal sentido, a partir de los desarrollos de los estudios de género, los estudios de masculinidades y particularmente de la teoría cuir, analizaremos en este artículo las estrategias y tácticas en intervenciones psicoanalíticas de un grupo terapéutico con jóvenes varones privadxs de su libertad. Las tensiones entre el psicoanálisis y los estudios de género, los feminismos y las masculinidades, nos proponen un debate fructífero para revisar tanto aspectos conceptuales de estos campos teóricos, como también las modalidades de abordaje clínico, contemplando la especificidad del contexto de encierro punitivo.

Al momento de reflexionar acerca de nuestras herramientas como psicoanalistas, se analizarán las lógicas de producción de un dispositivo terapéutico en una unidad penitenciaria, atendiendo a dos especificidades: las lógicas del encierro punitivo y los lazos sexo-afectivos (Colanzi, 2018) de los jóvenes varones privadxs de libertad; para ello partiremos de la noción de intervención, que atendiendo a estas particularidades y entendiendo la ética psicoanalítica orientada a la subversión del sujetx, se ve mutilada de no incluir las categorías de análisis y praxis de los estudios de género.

\section{Desarmar(se) varón: recorridos conceptuales entre los estudios de género y los aportes del psicoanálisis}

\footnotetext{
Te escribo para escribirme...lo que hoy por hoy siento es que yo, hoy, soy vos... Cada uno de nosotros es cada uno y todos los demás. (...) Y estas son las cartas, mi Viejo, que te quise escribir desde donde escribir no se podía y que te escribo hoy, mi Viejo, desde donde sí puedo, junto a una ventana que durante tantas eternidades no tuve... (Rosencof, 2000).
}

En este apartado analizaremos, a través de un dispositivo psicoanalítico en cárceles destinado a varones de 18 a 21 años, cuáles son las tensiones conceptuales del psicoanálisis y los estudios de género, los estudios de masculinidades y la teoría cuir. Este recorrido conceptual inicia con las discusiones epistemológicas del corpus psicoanalítico, delimitando la noción de sujetx como lugar de tensión de estos entrecruzamientos. Este dispositivo clínico fue diseñado en dos momentos, en tanto instancias necesarias para propiciar múltiples interrogantes acerca del so(gra)ma (Campagnoli, 2013), noción que refiere a la conjunción entre una apuesta performativa del cuerpo-lenguaje, que contempla la dimensión biológica del mismo.

Los momentos del dispositivo que analizaremos están articulados de manera necesaria, en un primer momento de escritura creativa y un segundo momento de grupo terapéutico. Ambas instancias propician un trabajo de (re)escritura como espacio de configuración de la intimidad (Zuckerfeld, 2017). Se propone así una doble acepción de la noción de espacio, por un lado emocional y por otro 
como espacio propio de escritura (Anzaldúa, 1987), contemplando los aportes que conjugan los feminismos y el psicoanálisis. Las producciones de escritura creativa suponen emergentes que permiten consonar en el trabajo de intervención grupal que se efectúa en un segundo momento y supone una trama encadenada que propone una reescritura so(gra)mática, aspecto que será desarrollado luego.

La relación entre el Psicoanálisis y las Teorías de Género es compleja. El primero introdujo un aporte nodal relativo a la conceptualización de sujetx, que marcó una ruptura con la concepción judeo - cristiana (Taylor, 1989). Esta noción de un sujetx que trasciende la razón se inscribe en un corpus teórico moderno, que fue conmovido con los cuestionamientos de las narrativas contrahegemónicas de la teoría cuir, siguiendo a Irene Fridman (2019).

El desarrollo de los estudios de las problemáticas de género y la desnaturalización de hábitos y concepciones culturales sobre la matriz sexo-genérica, conllevan a la reformulación de las concepciones teóricas tradicinonales del psicoanálisis (Zuckfeld, 2017). En esta línea, Marie-Hélène Brousse (2020) propone pensar las luces que los estudios de género pueden aportar al psicoanálisis para evitar por ejemplo la discriminación de las mujeres y progresar en la formulación de nuevos saberes.

Podemos identificar dos grandes interrogantes al psicoanálisis: 1) como construcción teórica de la modernidad que explica cómo advienen lxs sujetxs en nuestra cultura, adhiriendo a la construcción social de la masculinidad y la feminidad (Russo y Vallejo, 2011) 2) como estrategia clínica en un dispositivo político de intervención que patologiza la disidencia y se enfrenta a la discusión en torno a lo posible frente a las necroprácticas carcelarias (Estévez, 2018).

En relación con el primer punto, nos interesa señalar las dificultades que los jóvenes varones privadxs de libertad hallan en la configuración de las masculinidades en cárceles y de qué manera se torna necesaria una modalidad de intervención situada que apele a nuevas concepciones sobre el sujetx y sobre lo masculino. En tal sentido, Fridman plantea:

El psicoanálisis no solo ha descrito la construcción subjetiva diferenciada por género, sino que, de alguna manera, también ha tenido un efecto prescriptivo con relación a postulados que delinean los modos de ser atribuidos a cada género, como así también la ubicación de varones y mujeres dentro de la estructura falogocéntrica (privilegio masculino de enunciar) (Fridman, 2019, p. 12).

Fridman identifica un aspecto relevante para abordar la especificidad de las masculinidades, la idea del privilegio y cómo un corpus teórico moderno requiere ser revisado y problematizado atendiendo a la feminidad y masculinidades del SXXI.

En consonancia con lo anterior y dentro del primer punto señalado, es preciso referir a los cuestionamientos de las teóricas feministas relativas a la prescripción de una posición subordinada de la mujer en el psicoanálisis y podemos desplazar esto también a la construcción de masculinidades disidentes, es decir al modo de 
pensar(se) varón que no responde a los procesos de subjetivación y socialización rígidamente establecidos por la modernidad. Hay entonces una fragilización de las identificaciones tradicionales que exige una revisión conceptual dentro del psicoanálisis (Brousse, 2020, p. 42).

De esta manera, nos proponemos problematizar la práctica psicoanalítica para habilitar una escucha -desde otro lugar- de lo que el psicoanálisis ha dogmatizado (en términos conceptuales y técnicos por su origen moderno y patriarcal). Solo así será factible plantear abordajes que tengan realmente en cuenta la singularidad de mujeres, varones y disidencias (Fridman, 2019).

Dentro del recorrido conceptual del punto 1, es preciso problematizar la noción de sujetx que tomaremos en Lacan a partir de La subversión del sujeto y dialéctica del deseo en el inconsciente freudiano (Lacan, 1960), para advertir el lugar del sujetx, la relación del dicho y el inconsciente.

La intención de propiciar un espacio de intimidad para la inscripción so(gra)mática, parte de los desarrollos conceptuales lacanianos al interrogar al inconsciente para hallar una respuesta "que no sea del orden del arrebato, o del derribamiento, sino que más bien 'diga por qué"' (Lacan, 1960, p. 775). Podríamos situar que el lugar de desciframiento que refiere el autxr nos remite a la conceptualización del inconsciente en una voz interrogativa.

En función del primer punto de análisis, abrevaremos en la definición lacaniana del yo "que puede interpretarse como lugar de enunciación" (Lacan, 1960, p. 779). Revisaremos este concepto desde la teoría cuir, en la sujeción del yo que define Judith Butler (1993). Se conjugan entonces, recursivamente, las concepciones del psicoanálisis lacaniano, con los desarrollos y discusiones teóricas de la teoría cuir. El aspecto que hemos identificado, a partir de una visión de paralaje (Žižek, 2006), es el cuerpo que se desplaza al so(gra)ma para delimitar una cartografía emocional que se enriquece con los aportes de Butler.

Para Lacan el sujetx encuentra en la imagen alterada de su cuerpo el paradigma que tiñe el mundo de los objetos con "un tinte de hostilidad proyectando en él el avatar de la imagen narcisista, que, por el efecto jubilatorio de su encuentro en el espejo, se convierte, en el enfrentamiento con el semejante, en el desahogo de la más íntima agresividad" (Lacan, 1960, p. 788). En función del contexto situado, entendemos necesario efectuar una operación que despliega una inscripción de esta alteración como una vía de subversión posible con la noción de so(gra)ma, entre el cuerpo de la imagen especular y la inscripción del territorio del lenguaje.

El (des)encuentro del cuerpo especular y el cuerpo del lenguaje halla un intersticio de lo posible a partir de la noción de quiasmo. Siguiendo a Judith Butler (2004) el habla es corporal, pero el cuerpo excede al habla. La autora define al cuerpo como quiasmo, figura que según Nayla Vacarezza (2011), permite pensar la materialidad del cuerpo y la normatividad del lenguaje. 
Esta forma de juntura se resuelve con el concepto de so(gra)ma, que Manuel Asensi Pérez (en Campagnoli, 2013) propone al definir al cuerpo como escritura. Este término nos permite revisar la propuesta lacaniana y conciliar los efectos performativos (puesta en escena del yo) en la clínica.

En cuanto al segundo punto propuesto en este apartado, nos interrogamos sobre la posibilidad del psicoanálisis en un contexto como la cárcel, en donde no se controla la vida, sino que se despliegan prácticas para infringir dolor. En este sentido, la noción de necroprácticas (Mbembe, 2011; Estevez, 2018) nos permite identificar la necesidad de contribuir al debate en torno a las intervenciones psicoanalíticas en cárceles. El psicoanálisis en la cárcel requiere de las contribuciones conceptuales de la teoría cuir, al momento de establecer lo posible frente a la imposibilidad de la existencia frente a prácticas y discursos mortíferos, como los del Servicio Penitenciario Bonaerense (SPB). De esta manera, lo que podría pensarse como un impensable frente al marco de inteligibilidad moderno y patriarcal, se desplaza al ámbito carcelario en donde la primera forma de poder y control por el dolor son las lógicas sexo-genéricas (Butler, 1997). Las tecnologías de explotación y control de los cuerpos,de los dispositivos legal y administrativo, penitenciario, registran y sistematizan las vidas precarias (Butler, 2004) y las políticas de la muerte. Es así como el psicoanálisis sin un diálogo con recursos conceptuales y clínicos de las teorías de género, los estudios de masculinidades y la teoría cuir, es inviable en la cárcel.

Nos proponemos en este apartado analizar los aportes del psicoanálisis al momento de pensar las intervenciones con jóvenes, promoviendo un análisis crítico de los conceptos psicoanalíticos. Esto conlleva no sólo a problematizar los aportes de Freud y Lacan, sino también delimitar los desafíos teóricos de los aportes de los estudios de género, a los efectos de confeccionar un tejido teórico crítico que interpele tanto las categorías conceptuales, como también las intervenciones técnicas de lxs psicoanalistas. Juan Carlos Volnovich (2000) refiere al compromiso ético-político de lxs psicoanalistas feministas, que en este artículo se analizará en torno a la noción de "construir(se) - padre": "Nadie podrá ahorrarnos a los varones el trabajo y el gusto de enunciarnos 'padres' y nadie podrá ahorrarnos a los psicoanalistas - feministas ( $y$, cuando digo "los" psicoanalistas me refiero a los psicoanalistas varones) el trabajo teórico de bajar al padre del caballo de lo "simbólico" para hacerlo aparecer en lo 'real"” (Volnovich, 2000, p. 246).

La potencia de la interpelación de Volnochich nos lleva a problematizar no sólo la noción de intervención, sino también a poder delimitar que en los espacios terapéuticos en la actualidad no es posible pensar exclusivamente desde la interdisciplina, sino que es necesario abordar las problemáticas a la altura de la complejidad de la época de las subjetividades del capitalismo tardío, donde nos guían grandes preguntas que exigen múltiples herramientas que lxs psicoanalistas no podemos desconocer.

Lxs jóvenes que participan de los espacios clínicos nos impulsan a interrogarnos acerca de la dimensión etaria, que analizaremos a partir del concepto de acontecimiento 
(Badiou, 2011), ya que nos permite comprender lo que ocurre en la juventud y especialmente en la salida exogámica de este momento estructurante. Julio Moreno (1989) señaló que la noción de acontecimiento supone un cambio renovador, que podría tener tres tipos de desenlaces en la juventud frente a lo emergente perturbador de la pubertad: un acontecimiento, un trauma o una catástrofe (Moreno, 1989, p. 13). Dicho emergente es demarcado socialmente con ritos de pasaje, que en la cárcel tienen características particulares, vinculadas con el ejercicio de las violencias de las masculinidades hegemónicas. Este proceso supone la producción de algo radicalmente nuevo, irreductible a lo previo, aun cuando lo infantil y los discursos del régimen de género (Connell, 2015) tiñan estas prácticas (discursivas y no discursivas) en el acontecimiento de la juventud. En esta línea, las intervenciones psicoanalíticas - feministas del dispositivo grupal se centran en la posibilidad de propiciar la emergencia subversiva de lxs sujetxs de derechos, para reconfigurar un lugar de historización simbolizante de la trama análitica - feminista.

La escritura creativa, en un primer momento y el grupo terapéutico en un segundo tiempo, permiten reconfigurar la trama ficcional de lxs sujetxs, escribiendo(se) con otros varones y subvirtiendo las tramas de las masculinidades hegemónicas. Esto permitiría acceder a las huellas del pasado y de sus pérdidas estructurantes, tanto en lo que respecta a la interpretación de estas, como a la creación en análisis.

Desde la teoría cuir, la escritura analítica se inscribe en un cuerpo de lenguaje subversivo, que determina una biopolítica positiva, que es uno de los ejes estructurantes del dispositivo grupal. Siguiendo a Julián Ferreyra (2019), la escritura analítica, para Freud, es una construcción que requiere de ciertas ficciones del psicoanálisis. Esto supone que, en el trabajo analítico, las co-construcciones e invenciones ficcionales en un so(gra)ma, que está condicionado por la cárcel y por el clivaje de edad y género. En el espacio de taller, al trabajar escrituras en múltiples soportes, como por ejemplo escenas psicodramáticas en torno a las vivencias y emociones de ser varón, se plantea la escritura historizante que se interpreta en el espacio del grupo terapeútico. Esta operación nos lleva a delimitar nuestras intervenciones de manera compleja, no ya interdisciplinariamente, sino en la producción de tecnologías clínicas cuir, que proponemos en el presente artículo y denominaremos "ficciones so(gra)máticas". Nos interesa también precisar esta categoría con los aportes de Ferreyra, quien problematiza los entrecruzamientos del psicoanálisis y la teoría cuir:

El hacer psicoanalítico es clínico porque implica un acto ficcional aun cuando no haya ficción alguna, aun cuando se la tenga que producir, inventar. Nuestro saber se pone a prueba en las ficciones que producimos, de las cuales participamos. Y esto no es un verso romántico: es simplemente una posición ética. Recurrimos a la ficción por añadidura, o quizás más bien porque la necesitamos y por eso viene incluso a desearla. Podríamos re-bautizar lo que hacemos como ficcioanálisis. (Ferreyra, 2019, p.1). 
Las ficciones so(gra)máticas nos permiten desarmar los mandatos patriarcales del régimen de poder (Connell, 1989), así como también, atender a las preocupaciones y registros emocionales que la performance emocional masculina (Gosende, 2003) inscribe en lxs cuerpxs, generando padecimientos que se exacerban en la condición de privación de libertad.

En el grupo terapéutico, considerar las masculinidades y su inscripción so(gra) mática en tanto un factor de riesgo, nos orienta a explorar la salida catastrófica de la pubertad en lxs jóvenes encarcelados. Julio Moreno conceptualiza dicha salida, como insistencia de la fuerza perturbadora, que produce una caída de la estructuración anterior. Tomando los desarrollos de los estudios de masculinidades, podríamos situar que esta fuerza perturbadora está teñida de las exigencias de las masculinidades hegemónicas y del lugar de la condición juvenil (Silba, 2007), en la cual se conjugan los mandatos de las masculinidades, la punición del régimen de género, la pérdida estructurante y melancólica de la compulsión de la heteresoxualidad y el binarismo (Butler, 1993).

El reconocimiento de las pérdidas que obligan a un arduo trabajo de duelo (por la pérdida del cuerpo infantil, la de la imagen idealizada de lxs xadres, por el dolor de dejar atrás la infancia, entre otras pérdidas) obligan al sujetx a un trabajo minucioso que se enlaza con la estructuración melancólica que plantea Butler. La autora feminista sostiene que la operación de identificación y elección de objeto de amor en la infancia supone una pérdida originaria y estructurante, a la que se ve obligado el sujetx en una cultura heterosexual y en un régimen de poder sexogenérico. Esta pérdida originaria permanece cristalizada y se reactualiza en los mandatos de género de las masculinidades hegemónicas que se recrudecen en la situación de privación de libertad. La potencia de desarme(se) varón es un primer momento lógico de la subversión del sujetx en un espacio terapéutico para afrontar el trabajo de duelo y trascender la posición melancólica.

La intervención que propicia la construcción de "ficciones so(gra)máticas" permite pensar en un yo historizador - constructor (Rother de Hornstein, 1991), en continuo movimiento de aprehender, ficcionalizar sogramáticamente, interpretar y reescribir su propia historia. Es a partir de la escritura que se propicia un trabajo identitario con un doble objetivo: construir(se) un pasado (Aulagnier, 1991) y deconstruir(se) masculinidades.

La operación de construir(se) un pasado, que se advierte en el epígrafe de Rosencof, nos lleva a la conceptualización del "Yo soy" desde el psicoanálisis, entendiendo que los integrantes del taller llevan adelante un proceso de duelo propio de la condición juvenil (Seoane, 2014) y al mismo tiempo un trabajo psíquico que presenta las particularidades del contexto de encierro punitivo.

La escritura creativa cumple entonces un rol fundamental, en tanto una intervención con enfoque de género y de derechos respetuosa del plexo normativo (Ley Nacional de Salud Mental N. ${ }^{\circ 26.657) . ~ E l ~ a c t o ~ d e ~ e s c r i b i r ~ e s ~ u n a ~ a c c i o ́ n ~ q u e ~ c o l a b o r a ~ c o n ~ l a ~ p u e s t a ~}$ en memoria y en historia y posibilita un trabajo de (re)construcción del pasado, de 
la narrativa fantasmática de quienes asisten a los talleres y a los grupos terapéuticos. Esta operación de construir(se) un pasado es una tarea permanente y necesaria para investir ese momento de la autobiografía del "Yo" y proyectar en un futuro.

Las intervenciones en los talleres y en el grupo terapéutico exigen una ética que rompa con la imposición carcelaria y la deshumanización de lxs sujetxs. Esta ética supone un punto de intervención y un lugar de enunciación: "Para el psicoanálisis el sujeto nunca es una víctima, sino que está planteado como respuesta de aquello que le viene del Otro; pero el solo hecho de plantearse como respuesta invalida su consideración como víctima" (Greiser, 2012, p. 34).

De esta manera, podemos plantear que el doble trabajo de duelo que efectúan lxs jóvenes privados de libertad se debe a la puesta en forma de su historia libidinal, así como también la particularidad del duelo de la vivencia de masculinidad hegemónica en el contexto de encierro punitivo.

En cuanto a la cárcel, este espacio de castigo posiciona al analista en un lugar de borde o extimidad. Podemos afirmar que esa posición "marginal" se vincula con los abordajes de los feminismos al momento de pensar de qué manera en la construcción de esa autobiografía del Yo se conjugan los elementos sociales que caracterizan la identidad de género y la performance emocional masculina.

Frente a esto Irene Greiser propone los siguientes interrogantes:

¿Qué posición es la esperable para un analista que trabaja en instituciones? Cierta posición de extimidad, es decir no estar ni adentro ni afuera, en esos bordes; no estar totalmente integrados al lazo social que se determina desde las normas institucionales, sino hacer uso de ellas (Greiser, 2012, p. 38).

También podemos situar en estas historias, la dimensión política de lxs jóvenes privados de libertad. Claudia Cesaroni sostiene:

Se hablará de sus historias, porque en ellas hay elementos comunes con los miles de presos que pueblan las cárceles de nuestro país: pequeñas transgresiones a los 15 o 16 años; debilidades o imposibilidades familiares; ausencia del Estado; falta de un proyecto de vida; delitos más graves y luego, el daño y el dolor. A otras personas, a sus familias y a ellos mismos (Cesaroni, 2010, p. 13).

A su vez, este doble duelo se define en una performance emocional masculina, que se advierte en el so(gra)ma, en tanto un acto semiótico para la fratría, es decir para los otros varones que definen el "hacer(se) hombre". Los estudios de masculinidades nos permiten llevar adelante una tarea que exige una reflexividad continua, que ha sido posible a partir de los desarrollos del enfoque de género y la teoría cuir. Estos estudios establecen a la masculinidad en contraste con la feminidad y en tanto un objeto histórico y cultural que se inscribe en un régimen de género.

Acerca de las definiciones de masculinidades podemos delimitar un enfoque 
esencialista, caracterizado por una mirada reduccionista y arbitraria con pretensión de universalidad. De igual manera, Raewyn Connell (1995) señala que, desde el enfoque positivista, con un ethos que enfatiza los hechos, la masculinidad se define por lo que los varones realmente son. Connell sostiene que esta definición de masculinidad responde a la base lógica de masculinidad/feminidad en el campo de la psicología,

...cuyos ítems se validan al mostrar que ellos diferencian estadísticamente entre grupos de hombres y mujeres. Es también la base de esas discusiones etnográficas sobre masculinidad que describen el patrón de vida de los hombres en una cultura dada y lo que resulte lo denominan modelo de masculinidad (Tiger, 1969, en Connell, 1995, p. 4).

Connell advierte tres dificultades: primero, que las descripciones responden a un punto de vista que ya el feminismo había denunciado como la operación de "racionalización de las diferencias" (Maffia, 2007); segundo, la definición de escalas de masculinidad/feminidad se ordena a partir de una atribución social en la que las tipologías responden a una clasificación de género desde el sentido común. Es así que Connell refiere que "el procedimiento positivista descansa así en las propias tipificaciones que supuestamente están en investigación en la pesquisa de género" (Connell, 1995). En tercer lugar, según Connell, definir la masculinidad como "lo que-los-hombres-empíricamente-son”, es considerar exclusivamente las acciones y no el lugar de enunciación desde donde se producen las mismas.

Estas dificultades se deben a los desafíos que se presentan en los estudios de masculinidades. Deacuerdo con Mauro Koury (2010) estosestudiosse desarrollaron de manera significativa en los años 90 del siglo pasado, con la definición conceptual de las relaciones sociales de género (Scott, 1992; Connell, 1995). Estos avances contribuyeron a definir teórica y metodológicamente lo fundamental del análisis sobre las masculinidades, conjugando aspectos fisiológicos, psicológicos y sociales.

La posibilidad de concebir las masculinidades en términos sociales, culturales, relacionales y políticas permitiría establecer lo que Connell delimita como masculinidades hegemónicas. Esto complejiza la noción de masculinidad, incorporando elementos como la raza y la clase, desde una perspectiva interseccional de abordaje. De igual manera, posibilita la inclusión de la dimensión del poder y, por consiguiente, la del disciplinamiento de los modos de ser varón junto con el ejercicio de las violencias.

\section{Deconstruyendo masculinidades}

¿Qué es de-construir? ¿Todxs saben qué significa?... es como una cebolla, que tiene capas, vamos aprendiendo y nos ponen capas. Ahora las estamos sacando (N. Taller realizado el 28 de mayo de 2018. Unidad N. ${ }^{\circ} 9$ ). 
Las intervenciones clínicas con jóvenes privadxs de libertad presentan desafíos específicos y propios de una apuesta por deconstruir las masculinidades hegemónicas. Una categoría clave es la de masculinidades trágicas de Néstor Artiñano (2016), ya que nos permite identificar el malestar propio del ejercicio de las masculinidades hegemónicas, que en el decir de algunos de lxs destinatarixs sería "ser varón a la antigua" (M. taller realizado el 3 de julio de 2018. Unidad N. $\left.{ }^{\circ} 45\right)$.

La idea de "ser varón a la antigua" se vincula con la imposición de la masculinidad hegemónica, que impone una performance emocional masculina. Esta performance se advierte en la posición subjetiva y en el lugar de enunciación que hallan los varones privadxs de libertad que asisten a nuestros talleres. En tal sentido, analizaremos dos temáticas que constituyen emergentes de los talleres efectuados en las unidades antes mencionadas: el aborto y la prostitución.

En el marco de las discusiones sobre la media sanción en Cámara de Diputados de la Nación del proyecto por la despenalización del aborto, surgieron varios emergentes propuestos por los jóvenes con quienes interactuamos:

J. dijo que estaba indignado con el Ni una menos, por el aborto. Estaban todos de acuerdo con él. El comentó que ahora iba a aumentar el aborto y que la criatura no tenía nada que ver. Les consultamos entonces qué había que hacer antes y si ellos se cuidaban, si hablaban sobre sexualidad, sobre cuidarse. J., quien habló bastante al inicio del taller, dijo que era un tema tabú, algunos asentían, otros miraban callados. Otro de los jóvenes contó que él había tenido una novia que a los 15 años la obligaron a abortar, sin que le preguntaran a él qué quería hacer. Les señalamos que teniendo en cuenta que un compañero se había animado a decir algo sobre su intimidad, qué pensaba el resto. Otro compañero comentó que había que hacer con las mujeres que abortan lo mismo que con los del narcotráfico, perseguirlas (Crónica del taller del día 15 de junio de 2018. Unidad N. $\left.{ }^{\circ} 45\right)$.

El primer emergente que se advierte, es que luego de presentar la propuesta sobre los talleres acerca de las masculinidades, surgió como tema de interés el movimiento del \#NiUnaMenos. Algunos de los jóvenes lo conocían y lo vinculaban con los femicidios en nuestro país. Sin embargo, también aparece el \#NiUnaMenos asociado al aborto, argumento utilizado por los actores que se asocian al movimiento a favor de las dos vidas. Los comentarios también suponen una concepción de mujer que no tiene autonomía sobre su cuerpo y su decisión y que debería ser castigada por esto. Pese al intento de problematizar cómo hablar acerca de las sexualidades y los derechos sexuales y (no)reproductivos, prevalece una concepción rígida en donde lo que se advierte como imposición es no consultar a quien co-concibe. Artiñano define la masculinidad trágica a partir del pensar, ver y sentir, lo que nos permite analizar estas concepciones, propias de la dimensión del pensar, en cuanto a la idea imaginada de mujer-enemiga. 
Frente a las talleristas mujeres se desplegaron micromachismos de crisis, entendiendo estos en un contexto específico en donde comienzan a resquebrajarse los modos rígidamente establecidos de ser varón y mujer, por ejemplo, a través del uso de opiniones sobre la decisión autónoma sobre las cuerpas gestantes:

Luego de pautar quiénes querían escribir J. se acercó y comentó que había preparado un video sobre aborto. El video era una entrevista con un médico español del diario "El prisma". El título: ¿Cuándo empieza la vida humana? En la entrevista el médico comentaba sobre el inicio de la vida de un ser humano, con imágenes de fetos. También hacía referencia sobre el tiempo de desarrollo que necesita un embrión y un huevo. El médico hablaba también sobre la aspiración o práctica de AMEU, el misoprostol, los legrados y la conciencia social sobre el inicio de la vida humana. En el video se hacía referencia a un médico "abortero", Bernard Nathanson, quien era partidario del aborto y que al ver imágenes (que se veían en el video también, fetos desangrados, embriones) sobre aborto había decidido no llevar adelante esa práctica. Les preguntamos si habían visto los alegatos a favor del aborto y les dijimos que íbamos a llevarles los alegatos de Darío Z, el filósofo. Luego empezamos a debatir sobre la campaña sobre el aborto, por su despenalización y también sobre el lugar de los cuerpos de las mujeres. Pidieron ver nuestros pañuelos y les mostramos el pañuelo de la campaña (Crónica del taller del día 22 de junio de 2018. Unidad N. ${ }^{\circ} 45$ ).

Las actividades propuestas por quienes participan de los talleres constituyen un modo de investir libidinalmente el espacio del taller que se produce por medio de resistencias frente a temáticas que exigen una actividad reflexiva sobre su propia identidad de género. Asimismo, las propuestas que refuerzan una postura activa y de imposición, pueden ser leídas a partir de las lógicas de la performance emocional masculina, que requiere de una permanente constatación y demostración (Jimeno, 2004, en Artiñano, 2016).

Si la tarea de deconstruir supone "sacar capas" impuestas por la matriz sexogenérica que obliga a una performance rígida y violenta, también es posible pensar en nuevos actos semióticos y cambios en la performance emocional de las masculinidades:

Ya dando por finalizado el taller, W. contó que él si estuviera afuera iría a la marcha (por el Ni una menos) con nosotras, para pedir justicia por su tía que fue víctima de femicidio. Le dijimos que íbamos a ir por ella, nos agradeció y nos deseó mucha suerte. (Crónica del taller del día 1 de junio de 2018. Unidad N. $\left.{ }^{\circ} 45\right)$

La experiencia del "Yo soy" en la operatoria de la construcción de un pasado y de una masculinidad genera movimientos subjetivos que pueden ser fortalecidos por medio de las actividades, tanto en los espacios de talleres como en los grupos 
terapéuticos, que se nutren de los emergentes del taller a fin de aportar recursos para el despliegue de la tarea del trabajo de duelo de las masculinidades impuestas como "capas" y promover las co-construcciones de masculinidades contrahegemónicas.

\section{Lazos sexo-afectivos y masculinidades}

En este apartado del artículo se abordan algunos interrogantes suscitados en el trabajo clínico con jóvenes varones privadxs de libertad. En el dispositivo de grupos terapéuticos se articulan la dimensión del acceso a la salud y el derecho al cuidado (Pautassi, 2007) como ejes de una trama simbolizante que se teje a partir de la reescritura de la propia historia.

En el acceso a la salud lxs varones suelen presentar actitudes reticentes que se vinculan con la imposibilidad del autocuidado, en tanto un derecho, así como también con las dificultades al momento de la expresión de las emociones, como operatoria de sobreexigencia patriarcal. De esta manera, pensar un dispositivo clínico de atención grupal supone abordar en primera instancia el lugar de la construcción de las masculinidades y de la performance asociada a la misma. La performance emocional de género (Gosende, 2003), constituye un aporte que se sustenta en los desarrollos de la teoría cuir (Butler, 1989) que nos permite comprender las políticas de las emociones (Ahmed, 2014) como operatoria de una construcción patriarcal en la que tanto el sexo como el género suponen inscripciones so(gra) máticas teñidas de la fantasía de individualidad para los varones (Hernando, 2012) que impide tanto procesos de puesta en palabras del padecimiento, como también la posibilidad de demanda de cuidado, autocuidado y del derecho a cuidar.

En el presente apartado de abordarán emergentes del grupo terapéutico relativos al cuidado y al autocuidado, en vínculo con los lazos sexo-afectivos, para luego, en el siguiente apartado abordar la noción de derecho a cuidar en relación con las masculinidades. Los lazos sexo- afectivos están regulados por un régimen de género, que define los modos en que se establece el tipo de contacto entre varones y mujeres y en la cárcel determina las prácticas sexo - afectivas que despliegan las mujeres encarceladas.

Consideramos que los lazos sexo - afectivos constituyen un tipo de cuidado, en un sentido amplio, así como también un modo de relacionarse que refleja el lugar paradojal de los afectos (Colanzi, 2018). Al igual que el orden de género, ya mencionado, la matriz sexo - genérica (Butler, 1997) que organiza las identidades de género y las sexualidades, opera regulando los lazos sexo -afectivos de las personas y adquiere ciertas particularidades en la situación de privación de libertad.

En el trabajo analítico de los emergentes del grupo terapeútico, en la Unidad N.945 de la localidad de Melchor Romero, pudimos identificar una lógica de ejercicio de los lazos sexo-afectivos que subvierte lo que denominamos escena guionada de la heterosexualidad, dado que la posibilidad del lenguaje del amor y el ejercicio de la sexualidad están asociados a un momento de "pausa", de acuerdo con los dichos de 
lxs integrantes del grupo terapéutico.

El lugar de la realización emocional (Fridman, 2017) presenta diferencias de acuerdo con la identidad autopercibida, es por ello que en el trabajo analítico y en las co-construcciones de las ficciones so(gra)máticas de lxs integrantes del grupo terapéutico se apreciaron diferentes modos de lazos sexo-afectivos, teñidos por el guión de la heterosexualidad, pero con matices propios del contexto de encierro punitivo.

Las "ficciones so(gra)máticas" significan una "reconstrucción discursiva de una autobiografía construida por el 'je'" (Aulagnier, 1991), que incide en la performance emocional que se caracteriza por la iterabilidad y la posibilidad de subversión del yo. Las intervenciones del grupo terapéutico se orientan a la posibilidad de cuestionamiento del marco de inteligibilidad patriarcal, a partir de una "re-apertura de una pregunta, en relación con la posición identificatoria del 'je'" (Aulagnier, 1988, p. 163). Esta co-construcción se produce en un momento de encrucijada para la performance emocional masculina: la cárcel. Consideramos que este momento constituye una apuesta subjetiva para "desarmar(se) varón" y en este movimiento se produzca un lugar de encuentro de sí, para sí y para otrxs.

En el primer encuentro con el grupo se propuso una presentación con el nombre y una emoción que los definiera como varones. Este ejercicio propicia la expresión de las emociones y permite un momento de apertura y cierre de cada encuentro. Las definiciones de masculinidades que se expresaron se vinculaban con la masculinidad y el orden del "tener": un hijo, un auto, adrenalina, felicidad. De esta manera, en cada encuentro y proyecto de acontecimiento, se posibilita la apertura de interrogantes en torno al lugar de sí, de ser cuidado y de ser amado, dentro y fuera de la cárcel, para pensar(se) hoy como varón y después en continuidad con el trabajo terapéutico en el pabellón.

Los pares y las parejas ocupan un lugar central: "uno es consciente, vos elegís si vas al colegio o a la esquina, nadie te obliga". Se les preguntó si le decían algo en el barrio a aquel que elegía ir a la escuela y respondieron que no. Una frase que resonó fue "cuánto tenés, cuánto valés". En esta línea, las parejas fuera del penal aparecen ligadas a un estereotipo de mujer que ejerce cuidado y marca límites: "te tienen de los bigotes". El cuidado también aparece asociado a un control que emerge en el trato con las mujeres significativas fuera del penal (antes de caer detenidxs).

En relación con la ya mencionada escena guionada de la heterosexualidad, un modo de seducción sexo-afectiva asociado a la historia libidinal que permite el patriarcado, el boliche, fue recreado en las definiciones del grupo terapéutico: "Si es de confianza te va a contar", lo que ocurre con otros varones en ese espacio asociado con la seducción. El control y la confianza aparecen como moneda de cambio en la escena sexo-afectiva heterosexual: uno de lxs integrantes relató una situación en la cual, al quedarse dormido, su novia le agarra el dedo y desbloquea el teléfono para revisarlo. En función de esto manifestó que hay que (im)poner límites y reglas en la pareja porque de lo contrario "fuiste tú", "donde dejas que mande ella estás perdido". 
En las definiciones de los lazos sexo-afectivos construidos durante la situación de privación de libertad, algunos manifestaron que "Hay pibas que les gusta venir a la cárcel, las trata mejor el preso que uno en la calle, en la calle andan todos con la pipa, no les dan cabida, vienen a buscar amor a la cárcel, el preso les da amor". En el grupo también se planteó que las parejas de afuera "nos dejan tirados" y que durante el período de encierro punitivo despliegan la capacidad de "la charlita", estrategia de seducción que se sostiene con algunas mujeres durante la detención, momento de "vacaciones forzosas", cuyo propósito es "irse a la calle un ratito" y luego: "Borró casete, como dice Maluma".

Los modelos erótico - amorosos presentan características propias de la performance emocional masculina, así como también de la cárcel. El contexto vivenciado, en tanto "pausa", determina la vivencia y la escena guionada de la heterosexualidad, en la cual el espacio de la esquina (en referencia al lugar por excelencia de los jóvenes en los barrios) se desplaza a la cárcel, en algunos casos por las exigencias propias de las masculinidades.

Irene Fridman reflexiona sobre la definición de Hobbes, para pensar las lógicas de subjetivación y la escena amorosa: "Ella para él, él para el Estado" y qué ocurre cuando la cara del Estado es la de la criminalización y feminización del so(gra)ma, en la que la performance de género subvierte el lugar de proveedor y relanza un lugar, en ocasiones de sumisión y también de dependencia emocional - económica. Se aprecia que en el espacio de co-construcción de las ficciones so(gra)máticas la dependencia aparece teñida de vergüenza, así como también de una temporalidad asociada exclusivamente al encierro y luego "borró cassette", operando una imposibilidad de pensarse pasible de cuidado y amor, más allá de la condición de privación de libertad.

La plusvalía que se obtiene en las capacidades amorosas fuera del encierro, en el caso de los varones y la dependencia afectiva con mascarada de fantasía de individualidad, se subvierte en la cárcel como un "beneficio" para aquellas mujeres que advierten una ventaja en la escena amorosa de las rejas: "las trata mejor un preso, que uno de la calle". Se advierte también una exigencia ante estos varones, ya que la entrega de la mujer de la calle supone una exigencia sexual, aun cuando, como manifiestan en el grupo terapéutico, en muchas oportunidades no desean tener relaciones sexuales.

El apuntalamiento afectivo de las mujeres de afuera exige una contraprestación de virilidad y potencia, aspectos que también resultaron ser una exigencia varonil que influyó en el conflicto con la ley penal y los expone a dificultades para pensarse como sujetxs con capacidad de realización emocional.

En la contraprestación viril y en las dificultades en concebirse amados aparece nuevamente lo que Fridman describe como dificultades en la democratización real de las condiciones erótico -amorosas. ¿Cómo propiciar entonces interrogantes para reescribir la propia historia y así redefinir los lazos sexo-afectivos dentor y fuera de la cárcel? ¿Cómo revisar los privilegios de los cuerpxs de varones “ATR” (expresión 
"A todo ritmo" que remite a consumos culturales propios de un grupo etario y de un clivaje de clase que condiciona la construcción de la identidad de género masculina hegemónica) en la esquina y luego de la infantilización y explotación del estado punitivo en la cárcel?

Los celos y la performance emocional en los varones exigen también una puesta en forma de los conceptos psicoanalíticos y un interjuego de saberes con los estudios de género. En el grupo terapéutico, los lazos sexo-afectivos ocupan un lugar central: en un encuentro, ante la posibilidad de la negociación amorosa, uno de los jóvenes señala: "Si no ponés las reglas, fuiste tú". Este emergente es leído a partir de los recursos de los estudios de las masculinidades y los desarrollos del giro emocional a partir de la noción de lazo sexo-afectivo (Colanzi, 2018).

Los celos ocupan un lugar esencial en el escenario masculino y de no ser abordados también convellan al ejercicio de las violencias. Para ello es imprescindible ahondar en la "conflictiva alrededor de la lucha por la jerarquía y el poder que atraviesa el universo masculino" (Fridman, 2019, p. 32). Es así como en entre-dicho en el espacio terapéutico emerge en clave patriarcal y solamente desde una lectura sexodisidente es posible propiciar lo posible frente a lo imposible: desarmar el lugar normativo de la fratría y reconfigurar de manera disidente la posición jerárquica de los géneros (Fridman, 2019).

Podemos entonces formular una nueva pregunta: cómo subjetivar el dominio masculino para pensar la emergencia subjetiva de los varones más allá de la jerarquía de poder. ¿Cómo propiciar otras maneras posibles de validar la identidad masculina, sin la prescripción del dominio de la fratría? ¿Cómo ubicar al sujetx de la subversión del lenguaje, trascendiendo el dominio colonial del control de los cuerpos-territorio de las mujeres? (Fridman, 2019, p. 40).

Tomando los aportes de Juan Carlos Volnovich (2000) en el marco del psicoanálisis se ha concebido al padre a través de la figura habilitante de la madre, o por medio de la performance de prohibición, por medio del borde de lo prohibido frente al so(gra)ma del vínculo padre - hijx. Volnovich revisa el planteo pionero de Emilce Dio Bleichmar (1994): "el amor edípico de la niña con su padre se desarrolla fundamentalmente a través de la mirada (...), el padre mira el cuerpo erótico de su hija y la niña se convierte así, de entrada, en culpable de querer llamar la atención del padre" (en Volnovich, 2000, p. 238). Desnaturalizar el cuidado como una tarea asociada con la identidad de género femenina, para repolitizar este derecho, nos permitirá reconceptualizar los aportes del psicoanálisis y plantear la exigencia que sostiene Volnovich: "Habrá que construir al padre y, simultáneamente, habrá que construir los recursos teóricos que den cuenta de esa construcción”.

Las ficciones so(gra)máticas permiten (re)escribir marcas afectivas que suponen una práctica de repolitización del cuidado, a través de la puesta en palabras de las emociones en un contexto como la cárcel y resignificando un espacio de circulación del afecto entre varones. Podríamos delimitar que el grupo terapéutico se desplaza luego a la ranchada, lugar de compartir entre varones en el pabellón 
y en la celda, operación que puede entenderse como una práctica de affidamento masculunio (Luque, 2019). Este término, que remite a los lazos de confianza y político-estratégicos entre mujeres, puede "queerizarse", siguiendo a Cecilia Luque, permitiendo que también los varones resignifiquen sus lazos sexo-afectivos con el objeto de propiciar espacios de autocuidado y cuidado entre varones.

Asumimos el desafío político de propiciar ficciones so(gra)máticas para repolitizar el cuidado, entendiendo al mismo como eje fundamental para la subversión del sujetx en un modelo de criminalización creciente, donde la única forma de cuidado posible para lxs varones jóvenes privadxs de libertad ha sido el Estado punitivo.

Las ficciones so(gra)máticas constituyen un dispositivo posible para democratizar los lazos sexo-afectivos, en tanto una lógica de cuidado, de lxs sujetxs de derechos y en la reescritura de la propia historia, para transformar la historia.

\section{Reflexiones finales}

La propuesta central del artículo radica en problematizar los conceptos del psicoanálisis sobre la noción de sujetx e inconsciente, en articulación con la (des) subjetivación de las masculinidades en cárceles del SPB. A lo largo del texto se proponen discusiones que revisan e interpelan las nociones teóricas de sujetx y cuerpo en psicoanálisis, al momento de articular las intervenciones clínicas frente a jóvenes varones privadxs de libertad.

La escritura ocupa un lugar fundamental en la puesta en forma de la memoria y la historia del "Yo". En función de los desarrollos conceptuales de la teoría cuir, la escritura adquiere un lugar particular, que opera quiasmáticamente entre el cuerpo de las funciones biológicas y el cuerpo del lenguaje de la teoría cuir. Por esta razón proponemos la noción de ficción so(gra)mática.

Los emergentes de los espacios clínicos analizados son paradigmáticos de la tensión que se plantea con el psicoanálisis, en tanto un discurso moderno y falogocéntrico (Fridman, 2019). Problematizar estas dificultades del psicoanálisis y las posibles interpelaciones de los estudios de género, las masculinidades y la teoría cuir, hacen posible un diálogo complejo cuyos efectos son la configuración de dispositivos clínico políticas que se enfrentan con las necroprácticas carcelarias actuales.

La escritura entonces no es simplemente una excusa creativa, sino una subversión posible en el escenario so(gra)mático:

¿Por qué se escribe? ¿y para quién se escribe? Preguntamos antes de leer los poemas. Escribo para mí, para los demás contesta uno de los chicos. Escribo para volar.Intentamos entre todos descubrir de qué trata el poema (de Mauricio Rosencof) y T. dice que es para el papá que está muerto y él que está preso. Ahí comenzamos a hablar de la historia del escritor que era uruguayo y escribía debajo de la tierra. ¿hay otros que son él? Cuentan la historia de Carloncho que 
había estado en la Unidad 9 y ahora estaba afuera y tiene un restaurante en donde da laburo a lxs presxs. Unx de los chicxs dice que todxs dejamos algo en una persona. Yo hoy soy vos, vos mañana vas a ser yo (Crónica del taller del día 4 de junio de 2018 . Unidad N. ${ }^{\circ}$ 9)

Propiciar la elaboración del fondo de memoria del yo por medio de la escritura y los grupos terapéuticos supone también apostar por nuevas proyecciones del yo, deconstruyendo las masculinidades hegemónicas e imperantes.

\section{Referencias}

Ahmed, S. (2014). La política cultural de las emociones. Universidad Nacional Autónoma de México.

Anzaldúa, G. (1987). Borderlands/La frontera: The new mestiza. Aunt Lute Books.

Artiñano, N. (2016). Masculinidades trágicas Trayectorias de vida de hombres detenidos que han ejercido violencia y abuso sexual en el ámbito familiar. Tesis Doctoral en Trabajo Social. Universidad Nacional de La Plata.

Aulagnier, P. (1988). Como una zona siniestrada Trabajo de Psicoanálisis, 3(9), 161-173.

Aulagnier, P. (1991). Construir(se) un pasado. Revista de Psicoanálisis APdeBA, XIII, (3),441-467.

Badiou, A. (2011). El elogio del amor. La Esfera de los Libros.

Brousse, M. H. (2020). Lo femenino. Editorial Tres Haches.

Butler, J. (1997). Sujetos de sexo / género / deseo Feminaria, 10, 1-20.

Butler, J. (1993). Mecanismos psíquicos del poder. Ediciones Cátedra.

Butler, J. (1997/2004). Lenguaje, poder, identidad. Síntesis.

Butler, J. (2004). Vidas precarias: El poder del duelo y la violencia. Paidós.

Cesaroni, C. (2010). La vida como castigo: Los casos de adolescentes condenados a prisión perpetua en la Argentina. Grupo Norma Editorial.

Chaves, M. (2009). Estudios sobre juventudes en Argentina I. Universidad Nacional de La Plata.

Colanzi, I. (2015). (Per)versiones del patriarcado: mujeres y violencia institucional. Derecho $y$ Ciencias Sociales, 12, 8-32.
Colanzi, I. (2018). Los lazos sexo-afectivos: modos de ejercicio de cuidado en mujeres privadas de libertad. Derecho y Ciencias Sociales, 18, 121-137. https://doi.org/10.24215/18522971e028.

Colanzi, I. (2018). Hacedoras de memorias: testimonios de mujeres privadas de libertad en las tramas del poder punitivo (2012 - 2016). Tesis Doctorado en Ciencias Sociales. Facultad de Humanidades y Ciencias de la Educación. Universidad Nacional de La Plata.

Connell, R. (1987). Gender and power. Stanford University Press.

Connell, R. (1995). The social organization of masculinity. En Masculinities. Berkeley University of California Press.

Connell, R. (2015). Masculinidades. Universidad Nacional Autónoma de México.

Cook, R. y Cusack, S. (2009). Estereotipos de género. Perspectivas legales transnacionales. Profamilia.

Estévez, A. (2018). Biopolítica y necropolítica: ¿constitutivos u opuestos?. Espiral, Estudios sobre Estado y Sociedad, XXV(73), 9-43.

Ferreryra, J. (2019). Psicoanálisis, ficcioanálisis y contraficcioanálisis. Polvo.

Fridman, I. (2017). Mujeres y varones frente a las condiciones políticas del amor. Entre la autonomía y la soledad. En I. Meler (comp.). Psicoanálisis y género. Escritos sobre el amor, el trabajo, la sexualidad y la violencia (pp. 165-174). Paidós.

Fridman, I.(2019). Violencia de género y psicoanálisis. Agonías impensables. Lugar.

Gosende, E. (2006). Accediendo al género masculino. Dimensiones históricas, hermenéutica, reflexiva y política de la masculinidad. Subjetividad y 
Procesos Cognitivos, 5, 159- 198.

Greiser, I. (2012). Psicoanálisis sin diván. Los fundamentos de la práctica analítica en los dispositivos jurídico-asistenciales. Paidós.

Hernando, A. (2012). La fantasía de la individualidad: sobre la construcción sociohistórica del sujeto moderno. Katz Editores.

Koury Pinhe, M. G. (2010). Volverse hombre Ambigüedad y ambivalencia en la construcción del género masculino. Estudios Sociológicos, XXVIII(82), 135-168. El Colegio de México, A.C.

Lacan, J. (1960). La subversión del sujeto y dialéctica del deseo en el inconsciente freudiano. Siglo XXI.

Luque, C. (2020). Affidamento masculino: E arte queer del fracaso del varón patriarcal. Heterotopías, 3(5), 1-15.

Mbembe, A. (2011). Necropolítica. Melusina.

Maffia, D. (2007). Sujetos, política y ciudadanía. En S. Chaher y S. Santoro (Comps.), Las palabras tienen sexo (pp. 12 - 28). Artemisa Comunicación.

Moreno, J. (1989). Pubertad, historización en la adolescencia. Cuadernos de la APdeBa, 1, 11-37.

Rother de Hornstein, M. C. (1991). La elaboración de los duelos en la adolescencia. Revista de Psicoanálisis, 6.
Russo, L. y Vallejo, P. (2011). El amor y lo femenino. Editorial Tres Haches.

Segato, R. (2003). Estructuras elementales de la violencia. Universidad de Quilmes.

Silva, M. (2007). El baile de las pibas, las piñas de los pibes (o viceversa): sobre feminidades y masculinidades en jóvenes de sectores populares. En M. Chavez. (Comp.), Estudios sobre juventudes en Argentina I. Hacia un estado del arte (pp. 167 -199). EDULP.

Taylor, C. (1989). Sources of the self. The making of the modern identity. Harvard University Press

Vacarezza, N. (2011). Figuraciones del cuerpo con género. Paralelismo y quiasmo. Revista Latinoamericana sobre Cuerpos, Emociones $y$ Sociedad, 3, 6.

Volnovich, J. C. (2000). Generar un hijo: la construcción del padre. En I. Meler y D. Tajer (Eds.), Psicoanálisis y género: Debates en el foro. Lugar.

Žižek, S. (2006). Visión de paralaje. Fondo de Cultura Económica.

Zuckerfeld, M. (2017). Injuria a la intimidad: sobre el complejo de la mujer [madre] humillada. Revista de la Sociedad Argentina de Psicoanálisis, 20, 199212. 